\title{
Maybe there is an alternative after all?
}

\section{Rob Hopkins ${ }^{1}$}

Accepted: 22 April 2020 / Published online: 23 May 2020

(c) Springer Nature B.V. 2020

When I give talks, or facilitate groups, I do an exercise where I invite people to close their eyes and to join me in an act of collective time travel. I ask them to imagine that they are going 10 years into the future. The time they are travelling forward to is not Utopia, but those 10 years have been a time of the most remarkable social transformation in history. A mobilisation of people and movements, a cascade of positive change no-one in 2020 could even imagine. I invite them to explore it using their imagination with all its senses ${ }^{1}$.

They share their experience. "There are no cars". "There are no homeless people". "Birdsong is so much louder". "There are food gardens everywhere". "There's a strong sense of collective purpose". It often moves people deeply. There are sometimes tears.

As I write this, in Week 3 of the UK's coronavirus lockdown, I can walk out of my door and, remarkably, that world has, in part at least, arrived. Wildlife is returning to our towns and cities. People are growing food, and learning to cook, at a scale not seen for decades. Seed companies are overwhelmed. Airlines are grounded. Urban air quality has improved to levels previously unimaginable. Community spirit is palpable. Walking around today feels, in some ways, like that imagined future.

In 2006, I was one of the people who started the Transition movement ${ }^{2}$. Our aim was to explore what a response to climate change that started at the community scale would look like. We asked what can we do, here, with the resources that we have, and the people that we have? It started in my town of Totnes in Devon, and has since spread to thousands of communities, in over 50 countries.

The concept of resilience was key. Resilience was, at that time, framed as the ability of a system to 'bounce back' after a shock, to return to normal. But we always felt that missed

This article is part of the Topical Collection: Agriculture, Food \& Covid-19.

\section{Rob Hopkins}

robhopkins@transitionnetwork.org

1 Transition Network, Totnes, UK the point. What we aimed to do in Transition was to explore how we might 'bounce forward'. How to use that shock, or the anticipation of shock, to move forward to something different that better met our needs as people and communities.

Many Transition groups focus on food projects. There is much to learn from projects and research that was pioneered but never widely adopted, and also from projects already underway. Around 2010, several Transition groups, inspired by Simon Fairlie's 'Can Britain Feed Itself?' research ${ }^{3}$, created local versions of this. Our 'Can Totnes Feed Itself?' study ${ }^{4}$ mapped the land around the town, and the extent to which we could build a viable 'foodshed'. The same was done in Norwich and a few other places too.

We did follow up work, linking farmers to producers, evaluating the economic benefits that such an approach would bring ${ }^{5}$, but this work was never properly resourced or backed by local government. How differently would we be thinking about food security in the light of the coronavirus crisis if we had? Transition has been a testbed, a kind of self-organising, decentralised Silicon Valley of future food systems, and all that learning exists to be picked up now and built on, with a new impetus and momentum following this emergency.

My favourite food project to emerge from Transition is in Liège in Belgium. Ceinture Aliment-Terre Liégeoise ('The

\footnotetext{
1 This exercise is explained in more detail in Hopkins, Rob. 2019. From What Is to What If: unleashing the power of imagination to create the future we want'. White River Junction, Chelsea Green Publishing.

2 www.transitionnetwork.org.

${ }^{3}$ Fairlie, Simon. 2009. Can Britain Feed Itself? The Land. 7. https ://www.thelandmagazine.org.uk/articles/can-britain-feed-itself. Accessed 21 April 2020

${ }^{4}$ Hopkins, Rob, Thurstain-Goodwin, M, Fairlie, S. 2009. Can Totnes and District Feed Itself? Exploring the practicalities of food relocalisation. Working Paper Version 1.0. Transition Culture blog. https:// www.transitionculture.org/wp-content/uploads/Can-Totnes-Feed-Itsel farticle-revised-Sept-09.pdf Accessed 22 April 2020.

5 Ward, Fiona. 2012. Totnes and District Local Economic Blueprint. REconomy Project, Totnes. https://www.reconomy.org/wp-content/ uploads/2015/10/TD-Local-Economic-Blueprint-final_low_res.pdf Accessed 22 April 2020.
} 
Liége Food Belt') started with the question "what if, in a generation's time, the majority of food eaten in Liège came from the land closest to Liège?"6. In the past 5 years, they have created 21 new cooperatives and raised $€ 5$ million from local people. They have created vineyards, shops, distribution networks, a local currency, popular city centre shops. The Mayor told me "this is now the story of our city".

When I walked around Liège, visiting the different CATL projects, it was an emotional experience. Here I was, walking around in the vision I had spent years trying to help others to imagine, but it was a living, breathing, working reality.

The coronavirus has shown us, contrary to Hollywood movies, that when we need each other, we're there for each other. It has shown us that rapid transition is entirely possible when the will is there. It has shown us that we can, in fact, reimagine and rebuild the world. We know what we have to do, and we know it works. Now we just have a scale it up.
Publisher's Note Springer Nature remains neutral with regard to jurisdictional claims in published maps and institutional affiliations.

Rob Hopkins is the founder of the Transition movement and author of several books including The Transition Handbook and, most recently, From What Is to What If. In 2012, he was voted one of the Independent's top 100 environmentalists and was on Nesta and the Observer's list of Britain's 50 New Radicals. He has spoken at TEDGlobal and three TEDx events. He is an Ashoka Fellow, and holds a doctorate degree from the University of Plymouth and has received two honorary doctorates from the University of the West of England and the University of Namur. He is a founder of New Lion Brewery in Totnes, and a director of Totnes Community Development Society, the group behind Atmos Totnes, an ambitious, community-led development project. robhopkins.net

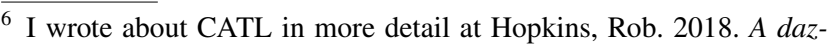
zlingly delicious taste of the future in Liége. https://www.RobHopkins .net blog post. https://www.robhopkins.net/2018/03/26/a-delicioustaste-of-the-future-in-liege/. Accessed 21 April 2020.
} 